\title{
Downregulation of hypoxia-inducible factor-1 $\alpha$ inhibits growth, invasion, and angiogenesis of human salivary adenoid cystic carcinoma cells under hypoxia
}

\author{
CHU XIAO $^{1 *}$, YI PAN $^{1 *}$, XIAOPING ZENG ${ }^{2}$, LINGYUN WANG $^{1}$, \\ ZIYANG LI $^{3}$, SONGXIN YAN ${ }^{1}$ and HONGMEI WANG ${ }^{1}$ \\ Departments of ${ }^{1}$ Pathophysiology and ${ }^{2}$ Immunology, Medical College of Nanchang University; \\ ${ }^{3}$ Queen Mary School of Nanchang University, Nanchang, Jiangxi 330006, P.R. China
}

Received December 28, 2017; Accepted June 27, 2018

DOI: $10.3892 / o r .2018 .6559$

\begin{abstract}
Surgical and medical treatments usually fail to completely remove the primary lesions of salivary adenoid cystic carcinoma (SACC), resulting in local recurrence due to its strong infiltration, hematogenous metastasis and other unique biological behaviors. Targeted gene therapy, including hypoxia-inducible factor-1 $\alpha$ (HIF-1 $\alpha)$ therapy, sheds new light on the treatment of salivary gland tumors. However, the mechanisms underlying the downregulation of HIF-1 $\alpha$ expression in SACC have not been well studied. The present study aimed to determine the effects of HIF-1 $\alpha$ downregulation on the proliferation, invasion, apoptosis, cell cycle and angiogenesis of hypoxic SACC- 83 cells, and to elucidate the molecular mechanisms underlying these effects. Western blot analysis was used to evaluate the protein expression levels of HIF-1 $\alpha$ and matrix metalloproteinase-2 (MMP-2). Angiogenesis and the protein expression of vascular endothelial growth factor (VEGF) were detected by tube formation assay of human umbilical vein endothelial cells and ELISA, respectively. It was revealed that short hairpin RNA was considerably downregulated following
\end{abstract}

Correspondence to: Professor Hongmei Wang, Department of Pathophysiology, Medical College of Nanchang University, 461 Bayi Road, Nanchang, Jiangxi 330006, P.R. China

E-mail: wanghongmay@hotmail.com

*Contributed equally

Abbreviations: DMEM, Dulbecco's modified Eagle's medium; ECM, extracellular matrix; ELISA, enzyme-linked immunosorbent assay; FBS, fetal bovine serum; GFP, green fluorescent protein; HIF-1 $\alpha$, hypoxia-inducible factor-1 $\alpha$; HUVECs, human umbilical vein endothelial cells; MMP-2, matrix metalloproteinase-2; PI, propidium iodine; PVDF, polyvinylidene fluoride; SACC, salivary adenoid cystic carcinoma; SEM, standard error of the mean; shRNA, short hairpin RNA; TBS, Tris-buffered saline; VEGF, vascular endothelial growth factor

Key words: salivary adenoid cystic carcinoma, HIF-1 $\alpha$, proliferation, invasion, angiogenesis overexpression of HIF-1 $\alpha$. In addition, downregulation of HIF-1 $\alpha$ inhibited the expression of VEGF and MMP-2, as well as the proliferation, invasion, migration, and tube formation of hypoxic SACC-83 cells, while inducing apoptosis in these cells. These results suggest that the downregulation of HIF-1 $\alpha$ may be a novel targeted therapy for SACC.

\section{Introduction}

Salivary adenoid cystic carcinoma (SACC) is one of the most common salivary epithelium-derived malignant tumor types, and is associated with persistent slow growth, perineural invasion, a high recurrence rate, and distant metastases (1). SACC accounts for $\sim 18 \%$ of all salivary gland malignancies in China (2). Due to neurotropic invasion and lung metastasis, surgery, radiotherapy and chemotherapy are often unsuccessful, and the recurrence rate is $16-85 \%$ (3). Furthermore, the rate of lung metastasis may be up to $40 \%$, with the 5-10-year survival rate as low as $37.4-41.8 \%$ (3). As the basic molecular mechanism of SACC carcinogenesis remains unclear, it is important to elucidate the malignant biological behaviors involved in SACC invasion and metastasis.

In human tissues, the normal oxygen partial pressure is $30-60 \mathrm{mmHg}$, while in the areas surrounding tumors, oxygen partial pressure is often $<5 \mathrm{mmHg}(4,5)$. When the tumor volume exceeds $3 \mathrm{~mm}^{3}$, a necrotic tumor center (hypoxic zone) is usually formed as a result of the inadequate oxygen, nutrients and energy supplied by new blood vessels (6). Hypoxia preferentially stimulates the overexpression of hypoxia-inducible factors (HIFs) and induces the expression of downstream genes via signal transduction pathways $(7,8)$. Thus, the overexpression of HIFs allows cells to adapt to hypoxic conditions and proliferate, resulting in high levels of invasion, metastasis and tolerance to radiation and chemotherapy (9-11). HIF-1 is a protein found in the nuclear extracts of the hepatocarcinoma cell line Hep-3B when cultured under hypoxic conditions. It specifically binds to the hypoxia response element (HRG) of the erythropoietin (EPO) gene (12-14). HIF-1 is a heterodimer consisting of $\alpha$ and $\beta$ subunits (15), and growing evidence indicates that the $\alpha$ unit (HIF-1 $\alpha$ ) is the functional subunit that is the unique limiting factor in oxygen regulation (16). The 
blockade of the degradation of HIF-1 $\alpha$ leads to the accumulation and overexpression of HIF-1 $\alpha$ under hypoxia, promoting tumor growth, neovascularization, distant metastases and chemoradiation resistance $(17,18)$. In addition, HIF- $1 \alpha$ is frequently overexpressed in various solid tumor tissues, and is associated with tumor invasion and poor prognosis (6). Thus, blocking HIF-1 $\alpha$ expression is a potentially important strategy for targeting anoxic tumor cells. Stoeltzing et al (9) constructed a $H I F l \alpha$-carrying plasmid (pHIF- $1 \alpha$ ) that, when transfected into gastric cancer cells, was associated with decreased tumor growth. Sun et al (19) reported that transfection with a plasmid containing antisense HIFl $\alpha$ downregulated HIF-1 $\alpha$ expression, resulting in the inhibition of vascular endothelial growth factor VEGF expression and a decrease in tumor microvessel density. However, the mechanisms underlying the suppression of cancer growth by HIF- $1 \alpha$ are complicated, and the effect of HIF-1 $\alpha$ expression on SACC has not previously been discussed.

The present study aimed to investigate the effects of HIF- $1 \alpha$ on the proliferation, invasion, metastasis, apoptosis, and angiogenesis of SACC-83 cells under hypoxia. The results revealed that the downregulation of $\mathrm{HIF}-1 \alpha$ inhibited the proliferation, growth, invasion, metastasis and angiogenesis of SACC-83 cells, while inducing morphological changes and apoptosis in these cells.

\section{Materials and methods}

Cells and reagents. SACC-83 cell lines were cultured in Dulbecco's modified Eagle's medium (DMEM; HyClone Laboratories, Inc., Logan, UT, USA) containing $10 \%$ fetal bovine serum (FBS; Biological Industries, Kibbutz Beit Haemek, Israel) and antibiotics $(100 \mathrm{U} / \mathrm{ml}$ penicillin and $100 \mu \mathrm{g} / \mathrm{ml}$ streptomycin) in a $5 \% \mathrm{CO}_{2}$ incubator at $37^{\circ} \mathrm{C}$. Following subculture, cells were placed in an anoxic incubator $\left(5 \% \mathrm{CO}_{2}, 5 \% \mathrm{O}_{2}\right.$, and $90 \% \mathrm{~N}_{2}$; Biospherix, Parish, NY, USA) for hypoxic treatment. Lipofectamine 2000 and OPTI-MEM were purchased from Thermo Fisher Scientific, Inc. (Invitrogen; Waltham, MA, USA). PBS, DMSO and bovine serum albumin (BSA) were purchased from Beijing Solarbio Science \& Technology Co., Ltd. (Beijing, China). The Annexin V/FITC kit and Matrigel were purchased from BD Biosciences (Franklin Lakes, NJ, USA). The human VEGF ELISA (cat. no. EHC108) kit was purchased from NeoBioscience (Shenzhen, China). Crystal violet staining solution was purchased from Beyotime Institute of Biotechnology (Haimen, China). Anti-HIF-1 $\alpha$ (cat. no. ab16066), anti- $\beta$-actin (cat. no. 8457), and anti-matrix metalloproteinase-2 (MMP-2; cat. no. ab92536) antibodies were purchased from Abcam (Cambridge, UK), while horseradish peroxidase-conjugated anti-mouse IgG (cat. no. ZB-2305) and anti-rabbit IgG (cat. no. ZB-2301) secondary antibodies were purchased from OriGene Technologies, Inc. (Beijing, China).

Transfection. The plasmid pGPU6/GFP/Neo, containing short hairpin RNA (shRNA) complementary to $H I F l \alpha$, was used to examine the function of HIF-1 $\alpha$. The pGPU6/GFP/Neo-HIF-1 $\alpha$-homo plasmid (Shanghai GenePharma, Shanghai, China) contained a promoter-driven green fluorescent protein (GFP) reporter. The most effective HIFl $\alpha$-targeted small interfering RNA (siRNA) sequence (5'-GCAGCTACTACATCACTTTCT-3') was transformed into shRNA (stem-loop-stem structure) and cloned into the pGPU6/GFP/Neo plasmid. A non-targeting sequence (5'-GTTCTCCGAACGTGTCACGT-3') was used to generate a negative control plasmid. SACC- 83 cells were cultured in 12 -well plates $\left(2 \times 10^{5}\right.$ cells/well $)$ with DMEM containing $10 \% \mathrm{FBS}$ for $24 \mathrm{~h}$ at $37^{\circ} \mathrm{C}$ in $5 \% \mathrm{CO}_{2}$ to $80 \%$ confluence. Subsequently, cells were transfected with HIFl $\alpha$ shRNA plasmid or empty plasmid using Lipofectamine 2000 reagent according to the manufacturer's instructions. Cells were transfected with $4 \mu \mathrm{g} / \mathrm{ml} H I F l \alpha$ shRNA plasmid and $4 \mu \mathrm{g} / \mathrm{ml}$ empty plasmid in OPTI-MEM. The culture medium was changed from OPTI-MEM to fresh DMEM supplemented with $10 \%$ FBS $6 \mathrm{~h}$ after transfection. The number of cells expressing GFP was determined using a fluorescence microscope (Olympus IX71; Olympus Corporation, Tokyo, Japan) $24 \mathrm{~h}$ after transfection, and the total cell number in the same field of view was determined under brightfield illumination. The transfected cell rate (\%) was estimated as the number of GFP-positive cells/total cell number x100. GFP-positive clones with G418 resistance were screened after 6-8 weeks of culture by selecting cells transfected with the sequence resulting in the best interference effect. G418-resistant cells were further cultured and used in subsequent experiments.

Western blot analysis. Cells from the three groups were collected after hypoxic culture for $48 \mathrm{~h}$ and washed twice with cold PBS. Total protein was isolated from cells using ice-cold RIPA for cell lysis (1\% Triton X-100, 50 mM Tris- $\mathrm{HCl}, \mathrm{pH}$ 7.4, $150 \mathrm{mM}$ $\mathrm{NaCl}, 0.1 \%$ sodium dodecyl sulfate, $1 \mathrm{mM}$ phenylmethylsulfonyl fluoride and $1 \mathrm{mM}$ ethylenediaminetetraacetic acid). Each mixture was centrifuged at $12,000 \mathrm{x} \mathrm{g}$, for $20 \mathrm{~min}$ at $4^{\circ} \mathrm{C}$, and the supernatant was collected and boiled for $10 \mathrm{~min}$ at $100^{\circ} \mathrm{C}$ for immunoblotting. The concentration of proteins was assessed using Bradford's method (20). Proteins (30 $\mu \mathrm{g})$ were separated by $10 \%$ SDS-polyacrylamide gel electrophoresis at $100 \mathrm{~V}$ for $2 \mathrm{~h}$ under reducing conditions and transferred to a polyvinylidene fluoride (PVDF) membrane (Beijing Solarbio Science \& Technology Co., Ltd.) using the electrophoresis apparatus. Membranes were blocked in 5\% nonfat milk in Tris-buffered saline containing $0.1 \%$ Tween-20 (TBST) for $1 \mathrm{~h}$ at room temperature. Subsequently, PVDF membranes were incubated with antibodies against HIF-1 $\alpha$ (1:500), MMP-2 (1:1,000), and $\beta$-actin $(1: 2,000)$ overnight at $4^{\circ} \mathrm{C}$. Then, the membranes were washed with TBST for 10 min three times and incubated with the appropriate secondary antibody as aforementioned $(1: 5,000)$ for $1 \mathrm{~h}$ at room temperature. Immunoreactive proteins were detected using the SuperSignal ${ }^{\mathrm{TM}}$ West Pico Chemiluminescent substrate (Thermo Fisher Scientific, Waltham, MA, USA) followed by exposure to Bio-Rad ChemiDoc XRS+ image analyzer (Hercules, CA, USA). Western blot signals were semi-quantified by densitometry using Image-Pro Plus 6.0 software (Media Cybernetics Inc., Bethesda, MD, USA). All western blot experiments were repeated at least three times and then were used to analyze the densitometry data.

Cell proliferation assay. Cell proliferation was determined by MTT assay (Sigma-Aldrich; Merck KGaA, Darmstadt, 
Germany). SACC-83 cells were plated on 96-well plates $\left(2 \times 10^{3}\right.$ cells/well) and cultured for 7 days under hypoxic conditions. Cell proliferation was documented every $24 \mathrm{~h}$ according to the manufacturer's protocol. Briefly, MTT solution (20 $\mu 1$, $2.5 \mathrm{mg} / \mathrm{ml}$ ) was added to each well and incubated at $37^{\circ} \mathrm{C}$. After $4 \mathrm{~h}$, the medium was removed, and DMSO (150 $\mu \mathrm{l})$ was added to each well to dissolve the formazan. Absorbance in each well was measured at $490 \mathrm{~nm}$ using an automatic multi-well spectrophotometer. The experiment was repeated at least three times.

Cell apoptosis analysis. Cells were cultured under hypoxic conditions for $48 \mathrm{~h}$. Subsequently, cells were collected and washed in ice-cold PBS prior to staining with Annexin V/FITC and propidium iodide (PI) solution for $15 \mathrm{~min}$ in the dark at room temperature. Cell apoptosis was examined using a FACSCanto flow cytometer (BD Biosciences). All experiments were repeated three times.

Cell cycle analysis. SACC- 83 cells were seeded in $60-\mathrm{mm}$ culture plates at a density of $1 \times 10^{5}$ cells/well for observing the cell cycle distribution. Cells were cultured under hypoxic conditions for $48 \mathrm{~h}$ and were then harvested by trypsinization, fixed with $70 \%$ ethanol and stored at $4{ }^{\circ} \mathrm{C}$ overnight. After washing with PBS, cells were incubated with $100 \mathrm{mg} / \mathrm{ml}$ RNase A and $50 \mathrm{mg} / \mathrm{ml}$ PI at room temperature for $30 \mathrm{~min}$ in the dark. The distribution of the cells was detected using a FACSCanto flow cytometer and analyzed using FlowJo 10.0.7 software (TreeStar, Inc., Ashland, OR, USA).

ELISA. The concentration of VEGF in SACC-83 cell culture medium was determined using human VEGF ELISA kit. SACC- 83 cells were cultured for $48 \mathrm{~h}$ to $90 \%$ confluency under hypoxic conditions. Following treatment, the culture medium was collected and stored at $-80^{\circ} \mathrm{C}$ for use in the ELISA. All experiments were performed at least three times, and the absorbance was measured at $450 \mathrm{~nm}$.

Tube formation assay. SACC- 83 cells were seeded in $60-\mathrm{mm}$ plates. Following adhesion, cells were cultured overnight in DMEM only and placed in the hypoxic incubator for an additional $24 \mathrm{~h}$. Human umbilical vein endothelial cells (HUVECs; $3 \times 10^{4}$ cells/well) were seeded on Matrigel-coated 96-well plates and incubated at $37^{\circ} \mathrm{C}$. Serum-free supernatant from shControl, shNC, and shHIF-1 $\alpha$ cells were collected and centrifuged at $716 \mathrm{x} \mathrm{g}$, for $5 \mathrm{~min}$ at $25^{\circ} \mathrm{C}$. The supernatants were then incubated with HUVECs at $37^{\circ} \mathrm{C}$ for $24 \mathrm{~h}$ under hypoxic conditions. The enclosed capillary structure of the tubes formed by HUVECs was observed, and three different fields per well were photographed (400x magnification) using an inverted microscope (DMi1; Leica, Wetzlar, Germany). The total tube length of the tubes in each field of view was measured using ImageJ 1.48 software (National Institutes of Health, Bethesda, MD, USA).

Wound healing assay. The migration of SACC-83 cells was measured using wound healing assays. SACC-83 cells $\left(5 \times 10^{5}\right.$ cells/well) were seeded into a 6 -well plate for $24 \mathrm{~h}$. Next, $10-\mu 1$ sterile pipette tips were used to create linear scratch wounds on the confluent cell monolayers. The three types of SACC-83 cells (shControl, shNC, and shHIF-1 $\alpha$ ) were cultured in serum-free medium. The scratch wounds were observed using an inverted microscope (DMi1; Leica Microsystems $\mathrm{GmbH}$ ), and images were acquired at 0 , 24 and $48 \mathrm{~h}$ (x200 magnification). The migration of cells in the wound area was quantified using ImageJ software. The scratch migration rate $(\%)$ was estimated as [(Scratch width at $0 \mathrm{~h}$ - Scratch width at 24 or $48 \mathrm{~h}$ )/Scratch width at $0 \mathrm{~h}]$ x 100 .

Matrigel invasion assay. A Transwell plate was pre-coated with $30 \mu \mathrm{l}$ DMEM containing 30\% Matrigel and added to the membrane of the upper chamber. The chamber was incubated at $37^{\circ} \mathrm{C}$ for $1 \mathrm{~h}$. A suspension $(400 \mu \mathrm{l})$ of SACC- 83 cells $\left(2 \times 10^{5}\right)$ at logarithmic growth phase in serum-free medium only was seeded in the upper chamber. DMEM (500 $\mu \mathrm{l})$ with $10 \%$ FBS was added to the lower chamber, and cells were cultured at $37^{\circ} \mathrm{C}$ in $5 \% \mathrm{CO}_{2}, 5 \% \mathrm{O}_{2}$, and $90 \% \mathrm{~N}_{2}$ for $24 \mathrm{~h}$. The liquid in the upper chamber and non-invasive cells on the membrane surface were removed with a wet cotton swab. The filter was fixed in $90 \%$ ethanol for $10 \mathrm{~min}$ and stained with crystal violet. The degree of invasion of SACC-83 cells was estimated under a microscope (x400 magnification) in five fields. Invasion was assessed quantitatively by counting the cells invading the lower side of the filter. The experiments were conducted in triplicate.

Statistical analysis. Data were analyzed using GraphPad Prism (version 5.0; GraphPad Software, Inc., La Jolla, CA, USA). Quantitative data are expressed as mean \pm standard error of the mean. Statistical analysis was performed using one-way analysis of variance with Tukey's post hoc test for $\geq 3$ groups. $\mathrm{P}<0.05$ was considered to indicate a statistically significant difference.

\section{Results}

Identification of stable cell lines. Western blot analysis was used to confirm the inhibitory effects of $H I F l \alpha$-targeted shRNA on the expression of HIF-1 $\alpha$ in SACC-83 cells. The results showed that the protein expression of HIF- $1 \alpha$ in SACC- 83 cells was significantly reduced in the shHIF-1 $\alpha$ group compared with levels in the shControl and shNC groups $(\mathrm{P}<0.01$ and $\mathrm{P}<0.05$, respectively; Fig. 1$)$.

Downregulation of HIF-1 $\alpha$ inhibits SACC-83 cell growth and induces cell apoptosis but has no significant effect on cell cycle progression under hypoxic conditions. The effect of HIF- $1 \alpha$ downregulation on the proliferation of SACC- 83 cells was assessed using a MTT assay. As demonstrated in Fig. 2A, the rate of proliferation of cells transfected with shHIF-1 $\alpha$ was significantly lower compared with that of cells transfected with shControl or shNC. The effect of HIF-1 $\alpha$ downregulation on SACC-83 cell apoptosis was also examined (Fig. 2B). Following shHIF-1 $\alpha$ transfection, the percentage of apoptotic SACC-83 cells increased to $13.09 \%$, which was significantly higher compared with the rates in the shControl (6.01\%) and shNC (5.13\%) groups ( $\mathrm{P}<0.05$, Fig. $2 \mathrm{C})$. Finally, the effect of HIF-1 $\alpha$ downregulation on cell cycle progression was examined using flow cytometry with PI DNA staining (Fig. 2D). As shown in Fig. 2E, the cell cycle distribution of the shHIF-1 $\alpha$ 

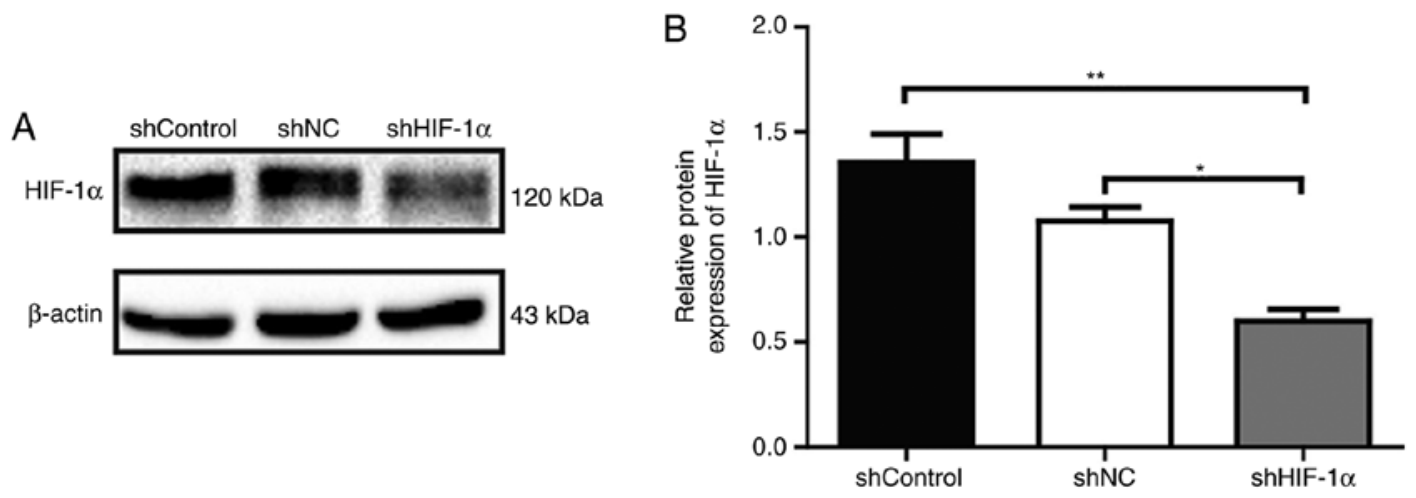

Figure 1. Protein expression of HIF-1 $\alpha$ in SACC-83 cells is inhibited by transfection with HIFl $\alpha$-targeted shRNA. (A) The inhibition efficiency of the HIFl $\alpha$-targeted shRNA was determined by western blot analysis. (B) Quantification of HIF-1 $\alpha$ expression. All data are expressed as the mean \pm standard error of the mean. " $\mathrm{P}<0.05$ vs. shNC group; ${ }^{* *} \mathrm{P}<0.01$ vs. shControl group. shControl group, wild-type SACC- 83 cells; shNC group, empty plasmid transfection group; shHIF-1 $\alpha$ group, HIFl $\alpha$-targeted shRNA transfection group; SACC, salivary adenoid cystic carcinoma; shRNA, short hairpin RNA; HIF-1 $\alpha$, hypoxia-inducible factor-1 $\alpha$; $\mathrm{NC}$, negative control.

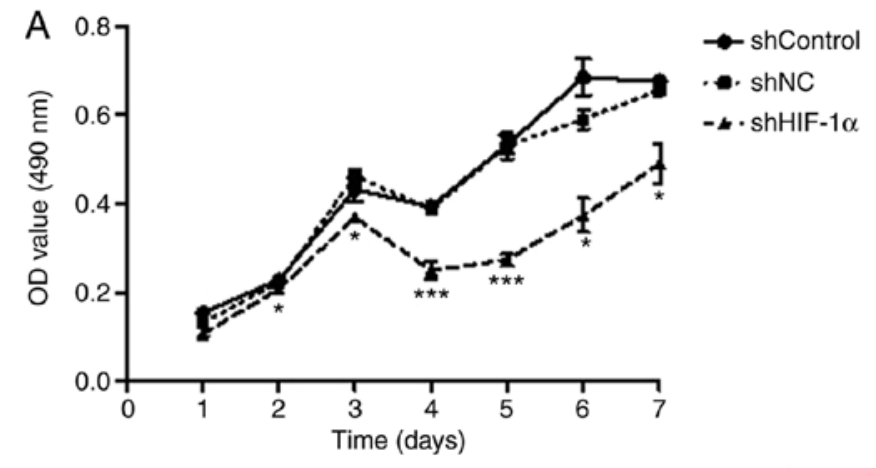

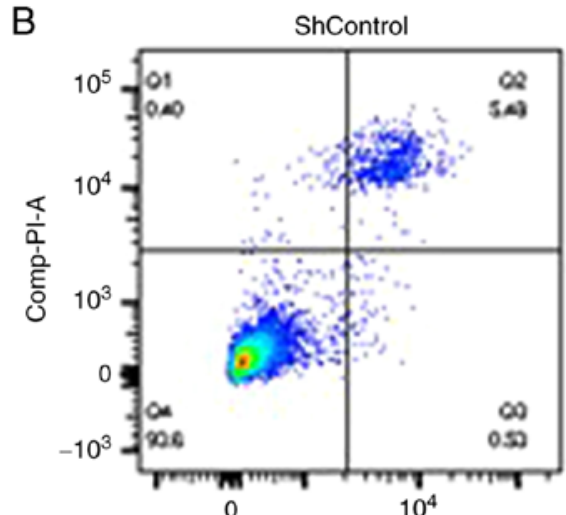

Comp-FITC-A::Annexin V

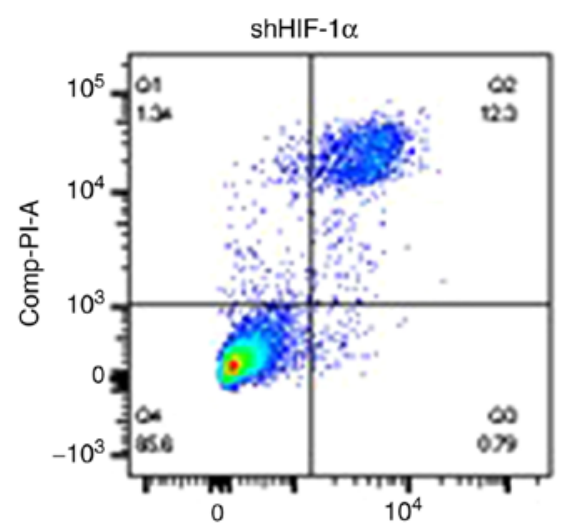

Comp-FITC-A::Annexin V

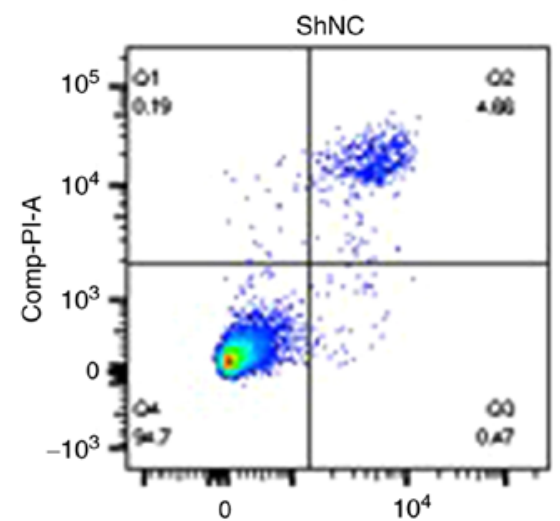

Comp-FITC-A::Annexin V

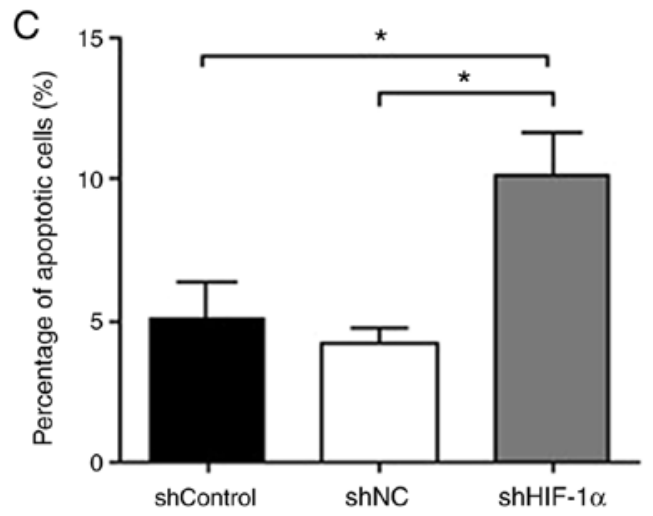

Figure 2. Downregulation of HIF-1 $\alpha$ significantly inhibits the proliferation and apoptosis of SACC-83 cells but does not affect the cell cycle. (A) Growth curves of the three groups of SACC-83 cells under hypoxia. (B) Cell apoptosis rates of different groups under hypoxia. (C) Percentage of apoptotic cells. 

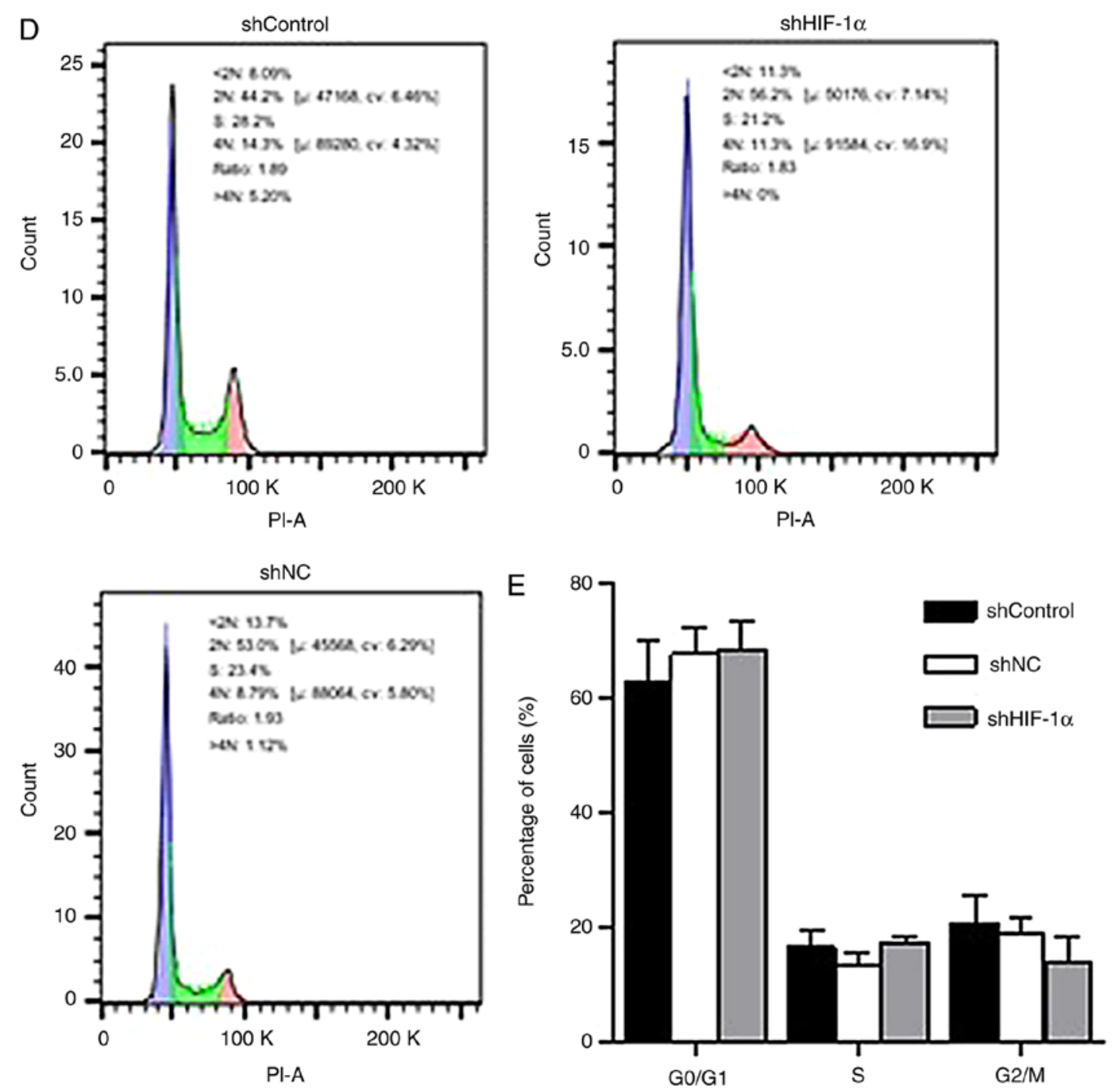

Figure 2. Continued. (D) Distribution of cells in each cell cycle phase. (E) No significant effects on the distribution of G0/G1, S or G2/M cells were noted. All data are expressed as the mean \pm standard error of the mean. "P $\mathrm{P}<0.05$ and ${ }^{* * *} \mathrm{P}<0.001$ vs. the shControl group and shNC group unless otherwise indicated. shControl group, wild-type SACC-83 cells; shNC group, empty plasmid transfection group; shHIF-1 $\alpha$ group, HIFl $\alpha$-targeted shRNA transfection group; SACC, salivary adenoid cystic carcinoma; shRNA, short hairpin RNA; HIF-1 $\alpha$, hypoxia-inducible factor-1 $\alpha$; NC, negative control; OD, optical density.

group was not significantly different from those in the shControl and shNC groups $(\mathrm{P}>0.05)$.

Downregulation of HIF-1 $\alpha$ decreased MMP-2 expression under hypoxic conditions. Western blot assays were performed to explore the effect of HIF-1 $\alpha$ downregulation on the expression of MMP-2, which is closely linked with tumor invasion and metastasis (21). As shown in Fig. 3A and B, in correspondence with the downregulation of HIF-1 $\alpha$, the expression of MMP-2 in the shHIF-1 $\alpha$ group was significantly lower compared with levels in the shControl and shNC groups $(\mathrm{P}<0.01)$.

Downregulation of HIF-1a suppresses SACC-83 cell invasion and migration under hypoxic conditions. Cell migration and invasion are important processes in tumor development and metastasis. Thus, the migration and invasion rates of SACC-83 cells under hypoxic conditions were assessed using wound healing and Matrigel Transwell assays. As shown in Fig. 4A and B, the downregulation of HIF-1 $\alpha$ in SACC-83 cells significantly reduced cell migration. The results indicated that the migration rate was $9.60 \%$ at $24 \mathrm{~h}$ and $22.08 \%$ at $48 \mathrm{~h}$ in the shHIF-1 $\alpha$ group, and these rates were significantly lower compared with those in the shControl $(23.71 \%$ at $24 \mathrm{~h}$ and $42.33 \%$ at $48 \mathrm{~h})$ and shNC $(23.35 \%$ at $24 \mathrm{~h}$ and $42.87 \%$ at $48 \mathrm{~h})$ groups $(\mathrm{P}<0.05)$. In addition, the in vitro Matrigel Transwell assay showed that the relative number of SACC-83 cells/field was significantly lower in the shHIF-1 $\alpha$ group (51\%) compared with in the shControl and shNC groups (Fig. 4C and $\mathrm{D} ; \mathrm{P}<0.001$ ), suggesting that the downregulation of HIF-1 $\alpha$ suppressed the mobility and migration of SACC- 83 cells.

Downregulation of HIF-1 $\alpha$ reduced angiogenesis and VEGF expression in hypoxic SACC-83 cells. Tumor angiogenesis not only provides adequate nutrition for the tumor, but also provides access for tumor metastasis (22). To study the effects of HIF-1 $\alpha$ downregulation on the angiogenesis of hypoxic SACC-83 cells, HUVECs were treated with cell culture medium derived from each cell type for $24 \mathrm{~h}$ and then the tube formation rate was evaluated in each group of 

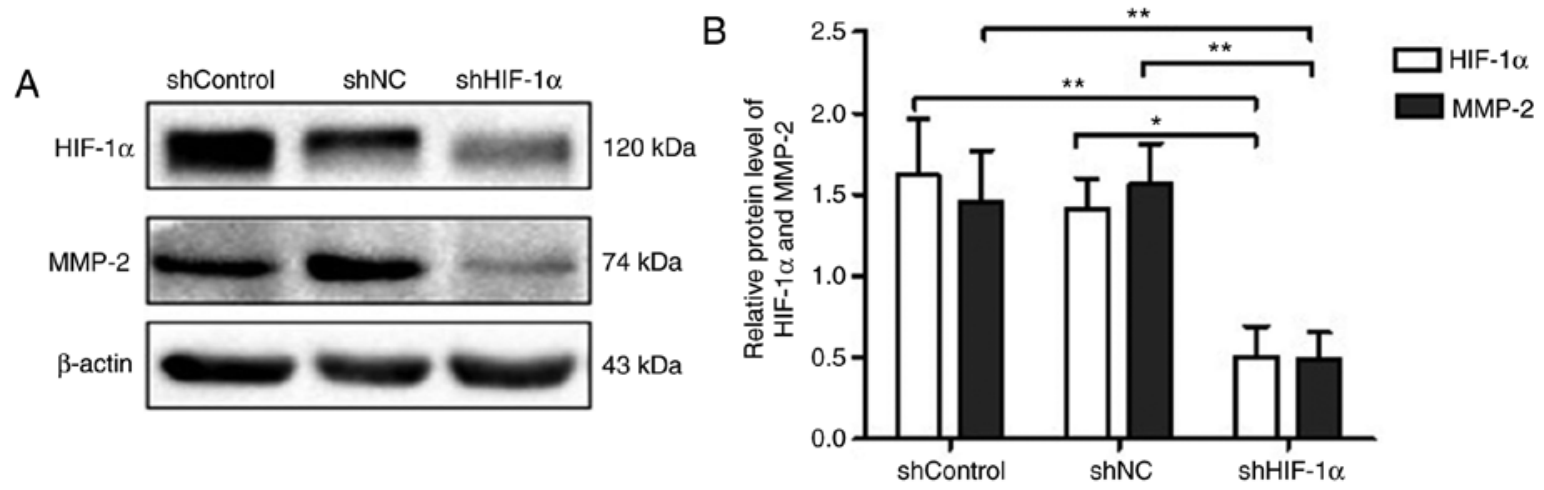

Figure 3. Effects of downregulation of HIF-1 $\alpha$ on MMP-2 expression in SACC-83 cells under hypoxia. (A) Western blot analysis of shControl, shNC and shHIF-1 $\alpha$ groups. (B) Quantification of MMP-2 and HIF-1 $\alpha$ protein expression. All data are expressed as the mean \pm standard error of the mean. "P<0.05, ${ }^{* *} \mathrm{P}<0.01$. shControl group, wild-type SACC-83 cells; shNC group, empty plasmid transfection group; shHIF-1 $\alpha$ group, HIFl $\alpha$-targeted shRNA transfection group; SACC, salivary adenoid cystic carcinoma; shRNA, short hairpin RNA; HIF-1 $\alpha$, hypoxia-inducible factor-1 $\alpha$; NC, negative control; MMP, matrix metalloproteinase.
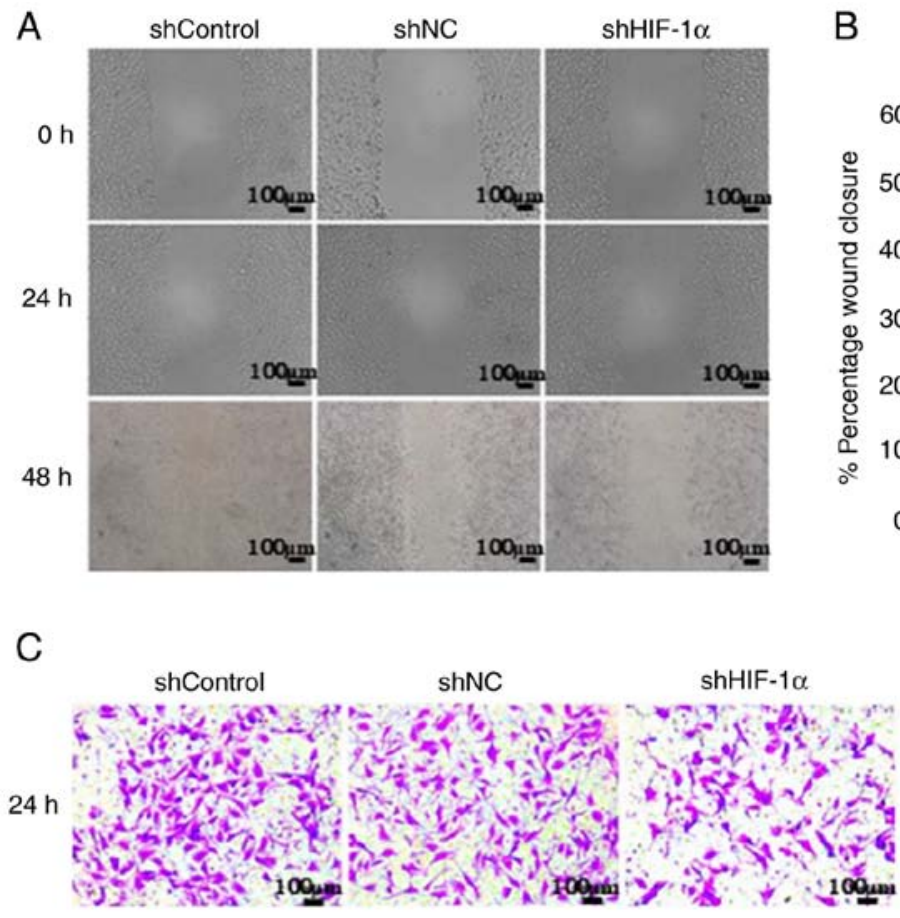

B
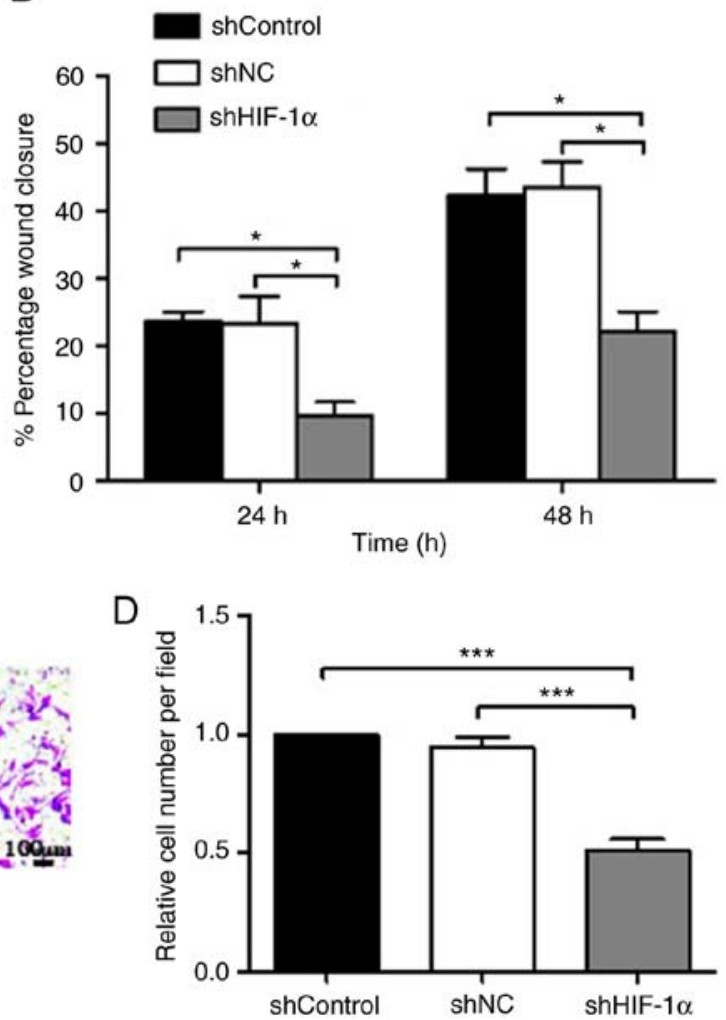

Figure 4. Downregulation of HIF-1 $\alpha$ inhibits the invasion and migration of SACC-83 cells. (A) Wound-healing assay of SACC- 83 cells at 0,24 and $48 \mathrm{~h}$. Scale bar, $100 \mu \mathrm{m}$. (B) Quantification of the effect of HIF-1 $\alpha$ on SACC-83 cell migration in the wound-healing assay. (C) The Transwell assay demonstrated the number of invasive cells in the shControl, shNC and shHIF-1 $\alpha$ groups. Scale bar, $100 \mu \mathrm{m}$. (D) Quantification of the number of invasive cells. The data are expressed as mean \pm standard error of the mean. ${ }^{*} \mathrm{P}<0.05,{ }^{* * *} \mathrm{P}<0.001$. shControl group, wild-type SACC-83 cells; shNC group, empty plasmid transfection group; shHIF-1 $\alpha$ group, HIFl $\alpha$-targeted shRNA transfection group; SACC, salivary adenoid cystic carcinoma; shRNA, short hairpin RNA; $\mathrm{HIF}-1 \alpha$, hypoxia-inducible factor-1 $\alpha$; $\mathrm{NC}$, negative control.

HUVECs. Compared with the shControl and shNC groups, the shHIF-1 $\alpha$ group exhibited significantly shorter tube lengths (Fig. 5A and B; $\mathrm{P}<0.001$ ).

A large number of clinical studies have reported that high expression of VEGF is associated with tumor microvessel density, the degree of malignancy and poor patient prognosis $(23,24)$. To investigate whether HIF-1 $\alpha$ downregulation affected the protein expression of VEGF, double-antibody ELISA was used. The results of the ELISA revealed that the protein expression level of VEGF was lower in the shHIF-1 $\alpha$ group compared with in the shControl and shNC groups (Fig. 5C; $\mathrm{P}<0.001$ and $\mathrm{P}<0.05$, respectively). The optical density values of the shControl and shNC groups were 49.27 and 42.53 , respectively, whereas that of the shHIF-1 $\alpha$ group was significantly lower (33.62). Together, these results suggest that a reduction in HIF-1 $\alpha$ expression significantly 

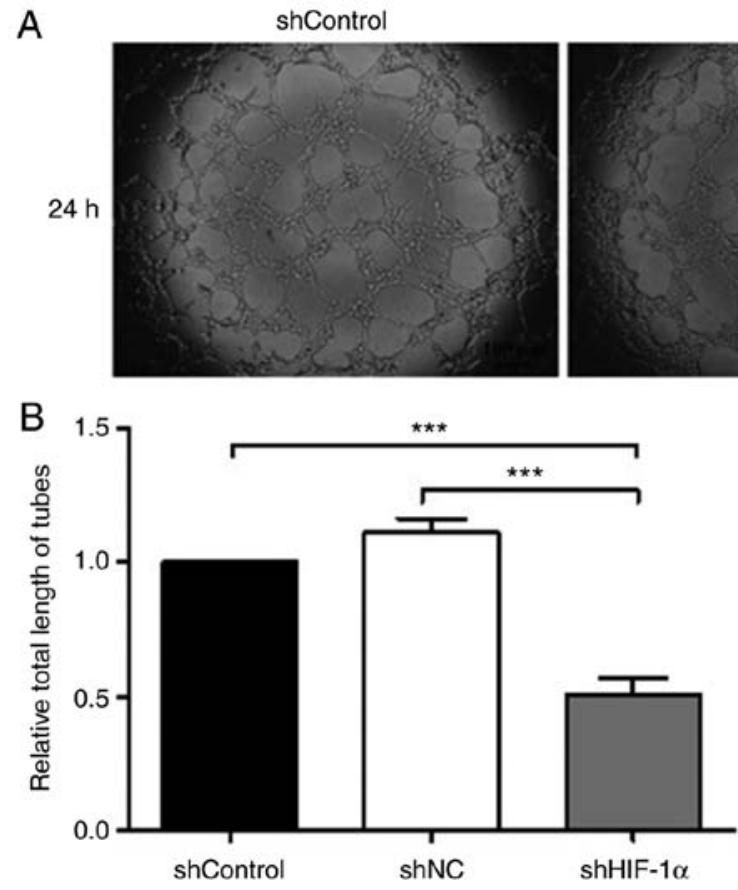

$\operatorname{shNC}$

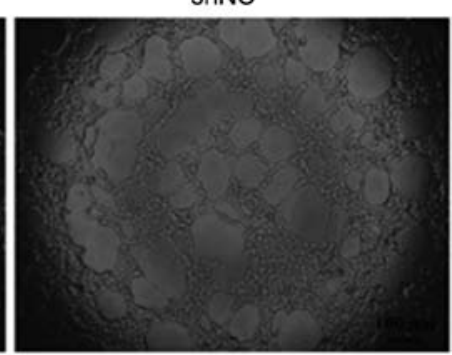

C

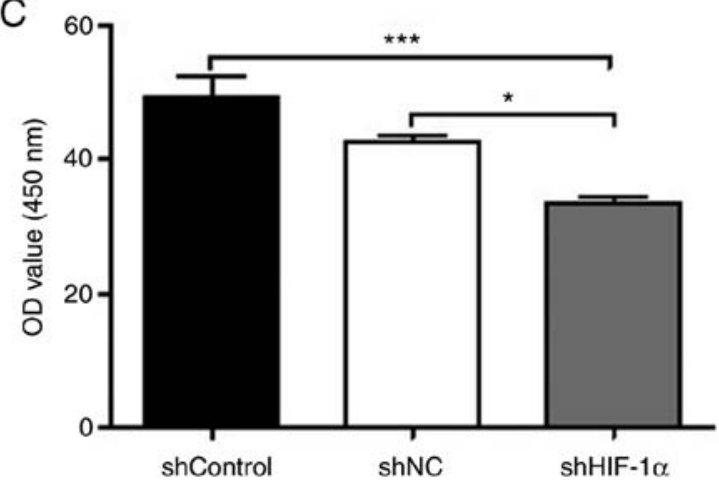

Figure 5. Downregulation of HIF-1 $\alpha$ inhibits tube formation and VEGF expression in SACC-83 cells. (A) Effects of downregulation of HIF-1 $\alpha$ on angiogenesis were verified by human umbilical vein endothelial cell tube-formation assays. Representative images of tube formation (magnification, $\mathrm{x} 400$ ). (B) Relative total length of tubes in each group of SACC-83 cells. (C) VEGF levels were determined by ELISA and the absorbance at 450 nm was measured. All data are expressed as the mean \pm standard error of the mean. ${ }^{*} \mathrm{P}<0.05,{ }^{* * * *} \mathrm{P}<0.001$. shControl group, wild-type SACC-83 cells; shNC group, empty plasmid transfection group; shHIF-1 $\alpha$ group, HIFl $\alpha$-targeted shRNA transfection group; SACC, salivary adenoid cystic carcinoma; shRNA, short hairpin RNA; HIF-1 $\alpha$, hypoxia-inducible factor-1 $\alpha$; NC, negative control; VEGF, vascular endothelial growth factor.

weakened tube-formation ability and reduced VEGF expression in SACC-83 cells.

\section{Discussion}

SACC is a common malignant tumor of the head and neck that exhibits distinct potential for invasion and distant migration (25). It has long been recognized that tumors are hypoxic, tumor hypoxia is a poor prognostic factor, and established tumors are protected by hypoxia and HIF-1 $\alpha$-mediated biochemical pathways (26). A previous study showed that the inhibition of HIF-1 $\alpha$ expression using specifically targeted siRNA could increase apoptosis and reduce migration in clear cell renal cell carcinoma 786-O cells (27). Consistent with these results, in the present study, we confirmed that HIF-1 $\alpha$ downregulation induced proliferation and apoptosis in hypoxic SACC cells.

As an important target of HIF-1 $\alpha$, VEGF is the most potent and selective angiogenesis-promoting factor, increasing microvascular permeability and inducing endothelial cell division, proliferation, and migration (28). HIF-1 $\alpha$ is regulated by the phosphatidylinositol 3-kinase and mitogen-activated protein kinase signaling pathways, which ultimately promote its expression (29). In this study, SACC-83 cells were cultured in a simulated hypoxic environment $\left(5 \% \mathrm{O}_{2}\right)$ and a RNA interference technique was used to downregulate HIF-1 $\alpha$ expression in SACC-83 cells. The results demonstrated that the downregulation of HIF-1 $\alpha$ significantly reduced the expression of VEGF in SACC-83 cells and that VEGF-associated tumor angiogenesis was significantly suppressed in HUVECs. HIF-1 $\alpha$ serves an important role in regulating the VEGF signal transduction pathway under hypoxic conditions. In the process of early angiogenesis, HIF-1 $\alpha$ not only increases the stability of $V E G F$ mRNA but also increases the transcriptional activity of $V E G F$, resulting in the transport of more oxygen and nutrients to the tumor and ultimately promoting tumor invasion and distant transfer (30). Reducing the expression of HIF-1 $\alpha$ in tumor cells may thus decrease the production of VEGF and inhibit tumor growth. HIF-1 $\alpha$ also serves a key role in the autocrine VEGF-VEGF receptor (VEGFR) signal transduction pathway, which may be another mechanism by which the downregulation of HIF-1 $\alpha$ inhibits tumor angiogenesis $(9,31,32)$

HIFs induce a variety of factors and enzymes associated with tumor invasion and metastasis, including MMPs (33). MMP-2 is the most widely distributed proteolytic enzyme in the MMP family, and is associated with tumor invasion and metastasis (34). Certain studies have reported that HIF-1 $\alpha$ promotes the invasion and metastasis of cervical cancer by downregulating E-cadherin expression and upregulating the expression of MMP-2 $(35,36)$. MMP-2 increases the extent of tumor vascularization and is an important component of the angiogenesis initiation system $(9,37)$. In hypoxic environments, tumor cells secrete large amounts of HIF-1 $\alpha$, inducing the secretion of MMP-2 by endothelial cells $(9,37)$. In the present study, it was demonstrated that the downregulation of HIF-1 $\alpha$ significantly attenuated MMP-2 expression. Furthermore, as expected, the results of wound healing and Transwell assays revealed that HIF-1 $\alpha$ significantly suppressed the migration and invasion of SACC cells.

In summary, the present study demonstrated that the downregulation of HIF-1 $\alpha$ significantly inhibited proliferation, 
invasion, migration and angiogenesis in hypoxic SACC-83 cells, and promoted apoptosis in this cell type. Additionally, HIF-1 $\alpha$ downregulation significantly attenuated the expression of MMP-2 and VEGF. The inhibition of angiogenesis may be useful for the treatment of neoplastic lesions and pro-angiogenic therapies may be important for future treatment of ischemic diseases (38). In the future, these findings should be confirmed in xenograft models and the signaling molecules underlying the effects of HIF-1 $\alpha$ on SACC should be elucidated through further research.

\section{Acknowledgements}

Not applicable.

\section{Funding}

The present study was supported by the Key Research and Development Program of Jiangxi Province (grant no. 20171BBG70120) and the Graduate Innovation Foundation of Nanchang University (grant no. cx2016357).

\section{Availability of data and materials}

The datasets used and/or analyzed during the current study are available from the corresponding author on reasonable request.

\section{Authors' contributions}

CX, YP, XZ, LW, ZL, SY and HW contributed to the conception, design and completion of the present study. CX and YP contributed equally to the experimental work and drafting of the manuscript. XZ analyzed the data and revised the manuscript critically for important intellectual content. LW and ZL performed the experiments and interpreted the results. SY produced the figures and HW contributed to study design.

\section{Ethics approval and consent}

Not applicable.

\section{Patient consent for publication}

Not applicable.

\section{Competing interests}

The authors declare that they have no conflict of interest.

\section{References}

1. Gondivkar SM, Gadbail AR, Chole R and Parikh RV: Adenoid cystic carcinoma: A rare clinical entity and literature review. Oral Oncol 47: 231-236, 2011.

2. Li LJ, Li Y, Wen YM, Liu H and Zhao HW: Clinical analysis of salivary gland tumor cases in West China in past 50 years. Oral Oncol 44: 187-192, 2008.

3. Umeda M, Nishimatsu N, Masago H, Ishida Y, Yokoo S, Fujioka M, Shibuya Y and Komori T: Tumor-doubling time and onset of pulmonary metastasis from adenoid cystic carcinoma of the salivary gland. Oral Surg Oral Med Oral Pathol Oral Radiol Endod 88: 473-478, 1999.
4. Rampling R, Cruickshank G, Lewis AD, Fitzsimmons SA and Workman P: Direct measurement of $\mathrm{pO}_{2}$ distribution and bioreductive enzymes in human malignant brain tumors. Int J Radiat Oncol Biol Phys 29: 427-431, 1994.

5. Kayama T, Yoshimoto T, Fujimoto S and Sakurai Y: Intratumoral oxygen pressure in malignant brain tumor. J Neurosurg 74: 55-59, 1991.

6. Zhong H, De Marzo AM, Laughner E, Lim M, Hilton DA, Zagzag D, Buechler P,Isaacs WB, Semenza GL and Simons JW: Overexpression of hypoxia-inducible factor 1alpha in common human cancers and their metastases. Cancer Res 59: 5830-5835, 1999.

7. Semenza GL: HIF-1: Mediator of physiological and pathophysiological responses to hypoxia. J Appl Physiol 88: 1474-1480, 2000.

8. Covello KL and Simon MC: HIFs, hypoxia, and vascular development. Curr Top Dev Biol 62: 37-54, 2004.

9. Stoeltzing O, McCarty MF, Wey JS, Fan F, Liu W, Belcheva A, Bucana CD, Semenza GL and Ellis LM: Role of hypoxia-inducible factor 1alpha in gastric cancer cell growth, angiogenesis, and vessel maturation. J Natl Cancer Inst 96: 946-956, 2004.

10. Samanta D, Gilkes DM, Chaturvedi P, Xiang L and Semenza GL: Hypoxia-inducible factors are required for chemotherapy resistance of breast cancer stem cells. Proc Natl Acad Sci USA 111: E5429-E5438, 2014.

11. Harada H: How can we overcome tumor hypoxia in radiation therapy? J Radiat Res 52: 545-556, 2011.

12. Semenza GL: Development of novel therapeutic strategies that target HIF-1. Expert Opin Ther Targets 10: 267-280, 2006.

13. Semenza GL and Wang GL: A nuclear factor induced by hypoxia via de novo protein synthesis binds to the human erythropoietin gene enhancer at a site required for transcriptional activation. Mol Cell Biol 12: 5447-5454, 1992.

14. Lee FS and Percy MJ: The HIF pathway and erythrocytosis. Annu Rev Pathol 6: 165-192, 2011.

15. Wang GL and Semenza GL: Purification and characterization of hypoxia-inducible factor 1. J Biol Chem 270: 1230-1237, 1995.

16. Pugh CW, O'Rourke JF, Nagao M, Gleadle JM and Ratcliffe PJ: Activation of hypoxia-inducible factor-1; definition of regulatory domains within the alpha subunit. J Biol Chem 272: 11205-11214, 1997.

17. Meijer TW, Kaanders JH, Span PN and Bussink J: Targeting hypoxia, HIF-1, and tumor glucose metabolism to improve radiotherapy efficacy. Clin Cancer Res 18: 5585-5594, 2012.

18. Łuczak MW, Roszak A, Pawlik P, Kędzia H, Lianeri M and Jagodziński PP: Increased expression of HIF-1A and its implication in the hypoxia pathway in primary advanced uterine cervical carcinoma. Oncol Rep 26: 1259-1264, 2011.

19. Sun X, Vale M, Jiang X, Gupta R and Krissansen GW: Antisense HIF-lalpha prevents acquired tumor resistance to angiostatin gene therapy. Cancer Gene Ther 17: 532-540, 2010.

20. Bradford MM: A rapid and sensitive method for the quantitation of microgram quantities of protein utilizing the principle of protein-dye binding. Anal Biochem 72: 248-254, 1976.

21. Shen W, Xi H, Wei B and Chen L: The prognostic role of matrix metalloproteinase 2 in gastric cancer: A systematic review with meta-analysis. J Cancer Res Clin Oncol 140: 1003-1009, 2014.

22. Deryugina EI and Quigley JP: Tumor angiogenesis: MMPmediated induction of intravasation- and metastasis-sustaining neovasculature. Matrix Biol 44-46: 94-112, 2015.

23. Chekhonin VP, Shein SA, Korchagina AA and Gurina OI: VEGF in tumor progression and targeted therapy. Curr Cancer Drug Targets 13: 423-443, 2013.

24. Xiong J, Yang Q, Li J and Zhou S: Effects of MDM2 inhibitors on vascular endothelial growth factor-mediated tumor angiogenesis in human breast cancer. Angiogenesis 17: 37-50, 2014.

25. Yan F, Wang C, Li T, Cai W and Sun J: Role of miR-21 in the growth and metastasis of human salivary adenoid cystic carcinoma. Mol Med Rep 17: 4237-4244, 2018.

26. Zimna A and Kurpisz M: Hypoxia-inducible factor-1 in physiological and pathophysiological angiogenesis: Applications and therapies. Biomed Res Int 2015: 549412, 2015.

27. Song T, Zhang X, Wang C, Wu Y, Cai W, Gao J and Hong B: MiR-138 suppresses expression of hypoxia-inducible factor $1 \alpha$ $(\mathrm{HIF}-1 \alpha)$ in clear cell renal cell carcinoma 786-O cells. Asian Pac J Cancer Prev 12: 1307-1311, 2011.

28. Roslavtceva VV, Salmina AB, Prokopenko SV, Pozhilenkova EA, Kobanenko IV and Rezvitskaya GG: The role of vascular endothelial growth factor in the regulation of development and functioning of the brain: New target molecules for pharmacotherapy. Biomed Khim 62: 124-133, 2016 (In Russian). 
29. Yu B, Miao ZH, Jiang Y, Li MH, Yang N, Li T and Ding J: c-Jun protects hypoxia-inducible factor-1alpha from degradation via its oxygen-dependent degradation domain in a nontranscriptional manner. Cancer Res 69: 7704-7712, 2009.

30. Qi L, Zhu F, Li SH, Si LB, Hu LK and Tian H: Retinoblastoma binding protein 2 (RBP2) promotes HIF-1 $\alpha$-VEGF-induced angiogenesis of non-small cell lung cancer via the Akt pathway. PLoS One 9: e106032, 2014.

31. Ravi R, Mookerjee B, Bhujwalla ZM, Sutter CH, Artemov D Zeng Q, Dillehay LE, Madan A, Semenza GL and Bedi A: Regulation of tumor angiogenesis by p53-induced degradation of hypoxia-inducible factor 1alpha. Genes Dev 14 34-44, 2000

32. Tang N, Wang L, Esko J, Giordano FJ, Huang Y, Gerber HP, Ferrara N and Johnson RS: Loss of HIF-1alpha in endothelial cells disrupts a hypoxia-driven VEGF autocrine loop necessary for tumorigenesis. Cancer Cell 6: 485-495, 2004.

33. Lee YA, Choi HM, Lee SH, Hong SJ, Yang HI, Yoo MC and Kim KS: Hypoxia differentially affects IL- $1 \beta$-stimulated MMP-1 and MMP-13 expression of fibroblast-like synoviocytes in an HIF-1 $\alpha$-dependent manner. Rheumatology 51: 443-450, 2012.
34. Tang YL, Liu X, Gao SY, Feng H, Jiang YP, Wang SS, Yang J, Jiang J, Ma XR, Tang YJ, et al: WIP1 stimulates migration and invasion of salivary adenoid cystic carcinoma by inducing MMP-9 and VEGF-C. Oncotarget 6: 9031-9044, 2015.

35. Wucherpfennig AL, Li YP, Stetler-Stevenson WG, Rosenberg AE and Stashenko P: Expression of $92 \mathrm{kD}$ type IV collagenase/ gelatinase B in human osteoclasts. J Bone Miner Res 9: 549-556, 1994.

36. Nagase H: Matrix metalloproteinases. A mini-review. Contrib Nephrol 107: 85-93, 1994.

37. Liu CT, Bi KW, Huang CC, Wu HT, Ho HY, S Pang JH and Huang ST: Davallia bilabiata exhibits anti-angiogenic effect with modified MMP-2/TIMP-2 secretion and inhibited VEGF ligand/receptors expression in vascular endothelial cells. J Ethnopharmacol 196: 213-224, 2017.

38. Wang F, Chang M, Shi Y, Jiang L, Zhao J, Hai L, Sharen G and Du H: Down-regulation of hypoxia-inducible factor-1 suppresses malignant biological behavior of triple-negative breast cancer cells. Int J Clin Exp Med 7: 3933-3940, 2014. 